\title{
Negative priming in same-different matching: Further evidence for a central locus of inhibition
}

\author{
W. TRAMMELL NEILL, L. SCOTT LISSNER, and JEAN L. BECK \\ Adelphi University, Garden City, New York
}

\begin{abstract}
Responses to recently ignored information may be slower or less accurate than responses to information not recently encountered. Such negative priming effects imply that the mechanism of selective attention operates on unattended, as well as attended, information. In the present experiment, subjects judged the second and fourth letters of five-letter strings (e.g., BABAB) as "same" or "different." Responses were slower when a target letter was identical to the distractors presented in the immediately preceding trial. This effect did not depend on which response was required on the current or preceding trial. The results suggest that ignored information is functionally disconnected from the response system as a whole, rather than from a specific response.
\end{abstract}

The process of attention is often regarded as a direct allocation of some limited processing resource to certain selected information (see, e.g., Broadbent, 1958; Deutsch \& Deutsch, 1963; Kahneman, 1973; Keele, 1973; Norman, 1968; Norman \& Bobrow, 1975; Shiffrin \& Schneider, 1977). According to this conception, a de facto "inhibition" of unattended information may occur because resources are allocated elsewhere (Posner \& Snyder, 1975). This inhibition is not regarded as an operation on the unattended information itself (Posner, 1982), and it does not discriminate between ignored stimuli and unpresented stimuli. Consequently, recently ignored stimuli should be processed at least as efficiently as stimuli that have not recently been presented. If ignored stimuli activate mental representations at all, persistence of this activation might actually facilitate subsequent processing.

In contrast, Neill $(1977,1979,1989$; Neill \& Westberry, 1987) and Tipper (1985; Tipper \& Cranston, 1985) have argued that ignored information is selectively inhibited, with the consequence that such information is temporarily less available for subsequent processing. Using a variation of the Stroop (1935) color-word task, Neill (1977) found that color naming was especially slow if the current color corresponded to the distractor word presented in the immediately preceding trial. (See also DalrympleAlford \& Budayr, 1966; Lowe, 1979, 1985; Neill \& Westberry, 1987.) Similarly, Tipper and Cranston (1985) found that naming a target letter was slowed if that letter had been presented as a distractor on the previous trial. Experiments done to investigate picture naming (Tipper, 1985 ) and lexical decision (Yee, in press) have shown that

This experiment was presented at the meeting of the Eastern Psychological Association, April 1988, in Buffalo, New York. The authors are indebted to Jai Dwivedi, Jenice Kral, Reuben Molloy, ElizabethAnne Neill, Bill Picciano, Denise Salmieri, and Kenneth Wind for assistance with data collection in this and related experiments. Correspondence should be directed to W. Trammell Neill, Department of Psychology, Adelphi University, Garden City, NY 11530. inhibition of processing also generalizes to semantic associates of the ignored stimuli.

The locus of such negative priming effects does not appear to be perceptual in a strict sense, since negative transfer occurs between physically dissimilar stimuli. In the Stroop task, the negative transfer occurs between a printed word and the corresponding color. Tipper and Driver (1988) found similar negative transfer between pictures and corresponding words. However, this leaves unresolved whether it is a specific response that is inhibited, or a more central, cognitive representation of the stimulus, or perhaps the connection between them. Tipper, MacQueen, and Brehaut (1988) found as much negative transfer between trials requiring separate vocal and manual responses as between trials requiring the same response modality. They concluded that selective inhibition must occur at a central locus that is tied to neither specific properties of the stimulus nor specific motor responses to the stimulus.

The present experiment extends and refines the conclusions of Tipper et al. (1988) by demonstrating negative priming in a same-different matching paradigm. In the Tipper et al. study, the remote possibility remains that cross-modal negative priming reflects the inhibition of a specific identification response, albeit in the opposite response modality. However, the matching paradigm allows a complete uncoupling of the overt responses ("same" or "different") from the particular target identities. Tipper (1985; Tipper \& Cranston, 1985; Tipper et al., 1988) suggests that the distracting stimulus is effectively denied access to the response system rather than to a specific response; if so, then negative priming should not depend on whether the current response is the same as that made in the previous trial.

The matching task provides a further methodological advantage over identification tasks: If vocal identification is required, premature vocalizations (e.g., " bl ... uh ... red!') yield spuriously fast reaction times, and scoring accuracy depends uncomfortably on the subjective judgment of the experimenter. Manual keypress responses (as 
in Neill \& Westberry, 1987) ameliorate the scoring problem; however, they obviously limit the number of stimuli that can be employed in an identification task. In a matching task, on the other hand, there is no constraint on the number of stimuli that can be mapped onto the two responses, "same" and "different."

\section{METHOD}

\section{Subjects}

Twenty-three Adelphi University undergraduates each participated in an individual session of approximately $30 \mathrm{~min}$, to meet an experiment requirement in an introductory psychology course.

\section{Stimuli and Apparatus}

Stimuli were selected from the entire set of 26 letters in the English alphabet. They were displayed in uppercase on an AMDEK Color-I Plus video monitor controlled by an Apple IIe microcomputer. Responses were made on the "open apple" and "filled apple" keys on the microcomputer keyboard. Response latencies were measured with a Mountain Hardware Apple Clock.

\section{Procedure}

Each trial began with the presentation of a plus sign $(+)$ on the video monitor for approximately $500 \mathrm{msec}$, which served as a fixation point and warning signal. This was replaced by a string of five adjacent letters, centered on the fixation position. The subjects were instructed to judge the second and fourth letters as "same" or "different," and to respond using the left or right index finger, respectively.

Trials were randomly selected to be same or different with equal probability. The following constraints determined the generation of stimulus strings: On one third of the trials, randomly selected, one or both target letters were identical to the distractor letter employed on the preceding trial. No letter appeared as a target on two successive trials, nor did any letter appear as a distractor on two successive trials. The same distractor letter was used for the first, third, and fifth positions of the string (e.g., CACDC). The current distractor letter was always different from the current target letters. As a result of these constraints, each letter sequence was either completely unrelated to that presented in the preceding trial, or related by identity between one or both target letters and the distractor presented in the preceding trial.

Each subject received 10 blocks of 100 trials. Each block was initiated by the subject when ready. On each trial, the stimuli remained in view until terminated by the subject's response. The subjects were instructed to respond as quickly as possible, but to avoid errors. If an incorrect response was made, a tone sounded and the message "ERROR" was displayed for approximately $500 \mathrm{msec}$. A blank period of approximately $500 \mathrm{msec}$ always preceded the presentation of the fixation signal for the next trial.

\section{RESULTS}

Geometric means of the reaction times in each condition were calculated for each subject, excluding error trials and trials following error trials. These means were entered into a $2 \times 2 \times 2$ analysis of variance with withinsubject variables of relatedness (related or unrelated to preceding trial), current trial type (same or different) and preceding trial type (same or different).

Responses on same trials $(M=792 \mathrm{msec})$ were significantly faster than on different trials $(854 \mathrm{msec})[F(1,22)=$ $20.77, p<.001]$. Responses on trials following same
Table 1

Mean Reaction Time (RT, in Milliseconds) and Percent Errors with Targets Related or Unrelated to Previous Distractors, as a Function of Current and Previous Trial Type

\begin{tabular}{lccccc}
\hline & \multicolumn{2}{c}{ Related } & & \multicolumn{2}{c}{ Unrelated } \\
\cline { 2 - 3 } \cline { 5 - 6 } Trial Type & RT & \% Error & & RT & \% Error \\
\hline \multirow{3}{*}{ Same } & \multicolumn{3}{c}{ Previous Same } & & \\
Different & 779 & 4.0 & & 766 & 4.0 \\
& 864 & 3.7 & & 842 & 3.8 \\
Same & \multicolumn{3}{c}{ Previous Different } & & \\
Different & 819 & 6.2 & & 803 & 5.4 \\
\hline
\end{tabular}

trials $(813 \mathrm{msec})$ were also faster than responses following different trials $(833 \mathrm{msec})[F(1,22)=4.93, p<.05]$. Current trial type also interacted with preceding trial type $[F(1,22)=7.19, p<.02]$. Responses on same trials following same trials $(773 \mathrm{msec})$ were fast, relative to same trials following different trials $(811 \mathrm{msec})$; however, responses on different trials were approximately equal following same trials $(853 \mathrm{msec})$ and following different trials (855 msec).

Of particular relevance to present hypotheses is that responses on related trials $(831 \mathrm{msec})$ were significantly slower than responses on unrelated trials $(815 \mathrm{msec})$ $[F(1,22)=15.26, p<.001]$. Relatedness did not interact with either current or preceding trial type (all $F \mathrm{~s}<1$ ). As is shown in Table 1, negative priming (related-unrelated) was comparable for same trials following same trials (13 msec), same trials following different trials $(16 \mathrm{msec})$, different trials following same trials $(22 \mathrm{msec})$, and different trials following different trials $(12 \mathrm{msec})$.

A similar analysis of variance was performed on percentages of error responses. More errors were made on same trials $(4.9 \%)$ than on different trials $(3.7 \%)[F(1,22)=$ $8.00, p<.01]$. In addition, more errors were made following different trials $(4.7 \%)$ than following same trials (3.9\%) $[F(1,22)=4.41, p<.05]$. These two variables interacted significantly $[F(1,22)=9.11, p<.01]$. More errors were made on same trials following different trials $(5.8 \%)$ than on same trials following same trials $(4.0 \%)$; however, errors on different trials were approximately equal following different trials (3.6\%) and following same trials $(3.8 \%)$. No effects involving the relatedness variable approached significance.

\section{DISCUSSION}

The reaction time advantage on same trials relative to different trials is a common finding, referred to as the "'fast-same effect"' (Krueger, 1978) or "same-different disparity" (Proctor, 1981). The paradoxically greater error rate on same trials is also typical. Krueger's (1978) "noisy operator" model suggests that same stimulus pairs are more likely to be misperceived as different than vice versa. Thus, when a pair is perceived as different, a "rechecking" process is more likely to occur, yielding 
longer reaction times. The interactions between current trial type and preceding trial type are not specifically predicted by the model, but they may possibly be accommodated by further assumptions. Such considerations are, however, beyond the scope of the present paper.

The result of immediate importance is that reaction times were reliably slower when the current target stimuli were related to the immediately preceding distractor stimuli. That negative priming occurs at all in the matching paradigm indicates that not just the response per se is inhibited. If, for example, the response "same" were inhibited, that response should be slowed on the next trial regardless of whether or not the target stimuli were related to the preceding distractors. The reliable related-unrelated difference implies that negative priming does depend on stimulus identity.

A more subtle question concerns whether a particular response to the distractor is inhibited, or if all responses to the distractor are inhibited. Response-specific inhibition could be realized in either of two ways: First, the connection between the distractor stimulus and the response actually made could be inhibited. This would predict more negative priming on same trials following same trials, and on different trials following different trials. However, not only does the predicted three-way interaction fail to achieve significance, but the magnitude of negative priming is somewhat larger for same trials following different trials, and for different trials following same trials.

Alternatively, response-specific inhibition could affect the response that is elicited by the distractor stimulus. Distractors may have always elicited a "same" response because the three distractors in a given string were identical, or a "different" response because they always differed from the targets. That the magnitude of negative priming was largest for different trials following same trials $(22 \mathrm{msec})$ is consistent with the latter possibility. However, across several replications of the main results (e.g., Neill \& Lissner, 1988), no consistent ordering of response sequences has been found. Therefore, it seems likely that negative priming is truly independent of the particular response sequence.

The present results are most consistent with the position that ignored stimuli are denied access to the response system as a whole. Neill (1979) assumed that selective inhibition works to directly reduce the activation of activated cognitive representations. Tipper (1985; Tipper \& Cranston, 1985) has suggested, however, that cognitive representations may be "isolated from the control of action" without actually reducing their activation. (See Lowe, 1979, for some relevant evidence.) Thus, the cognitive representation of a distracting stimulus may somehow be "tagged" as information to be ignored. When that information subsequently becomes task-relevant, its tag may hamper the selection of an appropriate response. In either case, the mechanism of selective attention involves operations on unattended information; indeed, such information might more properly be regarded as "disattended."

\section{REFERENCES}

Broadbent, D. E. (1958). Perception and communication. London: Pergamon.

DalRYMPle-Alford, E. C., \& BuDAYr, B. (1966). Examination of some aspects of the Stroop color-word test. Perceptual \& Motor Skills, 23, $1211-1214$

Deutsch, J. A., \& Deutsch, D. (1963). Attention: Some theoretical considerations. Psychological Review, 70, 80-90.

Kahneman, D. (1973), Attention and effort. Englewood Cliffs, NJ: Prentice-Hall.

Keele, S. W. (1973). Attention and human performance. Pacific Palisades, CA: Goodyear.

Krueger, L. E. (1978). A theory of perceptual matching. Psychological Review, 85, 278-304.

LowE, D. G. (1979). Strategies, context, and the mechanism of response inhibition. Memory \& Cognition, 7, 382-389.

LowE, D. G. (1985). Further investigations of inhibitory mechanisms in attention. Memory \& Cognition, 13, 74-80.

NeILL, W. T. (1977). Inhibitory and facilitatory processes in attention. Journal of Experimental Psychology: Human Perception \& Performance, 3, 444-450.

NEILl, W. T. (1979). Switching attention within and between categories: Evidence for intracategory inhibition. Memory \& Cognition, 7, 283-290.

NeILL, W. T. (1989). Lexical ambiguity and context: An activationsuppression model. In D. S. Gorfein (Ed.), Resolving semantic ambiguity (pp. 63-83). New York: Springer-Verlag.

NeILL, W. T., \& Lissner, L. S. (1988, April). Attention and selective inhibition in alphanumeric character matching. Paper presented at the meeting of the Eastern Psychological Association, Buffalo, NY.

NeILL, W. T., \& Westberry, R. L. (1987). Selective attention and the suppression of cognitive noise. Journal of Experimental Psychology: Learning, Memory, \& Cognition, 13, 327-334.

Norman, D. A. (1968). Toward a theory of memory and attention. Psychological Review, 75, 522-536.

Norman, D. A., Bobrow, D. G. (1975). On data-limited and resource-limited processes. Cognitive Psychology, 7, 44-64.

POSNER, M. I. (1982). Cumulative development of attention theory. American Psychologist, 37, 168-179.

POSNER, M. I., \& SNYDER, C. R. R. (1975). Facilitation and inhibition in the processing of signals. In P. M. A. Rabbitt \& S. Dornic (Eds.), Attention and performance $V$ (pp. 669-682). New York: Academic Press.

Proctor, R. W. (1981). A unified theory for matching-task phenomena. Psychological Review, 88, 291-326.

Shiffrin, R. M., \& SCHNEIDER, W. (1977). Controlled and automatic human information processing: II. Perceptual learning, automatic attending, and a general theory. Psychological Review, 84, 127-190.

STROop, J. R. (1935). Studies of interference in serial verbal reactions. Journal of Experimental Psychology, 18, 643-662.

TIPPER, S. P. (1985). The negative priming effect: Inhibitory priming by ignored objects. Quarterly Journal of Experimental Psychology, 37A, 571-590.

TiPper, S. P., \& Cranston, M. (1985). Selective attention and priming: Inhibitory and facilitatory effects of ignored primes. Quarterly Journal of Experimental Psychology, 37A, 591-611.

TIPPER, S. P., \& DrIVER, J. (1988). Negative priming between pictures and words in a selective attention task: Evidence for semantic processing of ignored stimuli. Memory \& Cognition, 16, 64-70.

TIPPER, S. P., MAcQueen, G. M., \& Brehaut, J. C. (1988). Negative priming between response modalities: Evidence for the central locus of inhibition in selective attention. Perception \& Psychophysics, 43, 45-52.

YEE, P. L. (in press). Inhibition processes in selective attention: Negative priming and cognitive masking. Quarterly Journal of Experimental Psychology.

(Manuscript received April 28, 1989; revision accepted for publication June 4, 1990.) 